\title{
Appraisal of Brain Connectivity in Radiologically Isolated Syndrome by Modeling Imaging Measures
}

\author{
Antonio Giorgio, ${ }^{1}$ Maria Laura Stromillo, ${ }^{1}$ Alessandro De Leucio, ${ }^{1}$ Francesca Rossi, ${ }^{1}$ Imke Brandes, ${ }^{1,2}$ Bahia Hakiki, ${ }^{3}$ \\ Emilio Portaccio, ${ }^{3}$ Maria Pia Amato, ${ }^{3}$ and Nicola De Stefano ${ }^{1}$ \\ ${ }^{1}$ Departments of Medicine, Surgery, and Neuroscience, University of Siena, 53100 Siena, Italy, ${ }^{2}$ University of Osnabrück, 49076 Osnabrück, Germany, and \\ ${ }^{3}$ Department of Neurology, University of Florence, 50121 Florence, Italy
}

We hypothesized that appraisal of brain connectivity may shed light on the substrate of the radiologically isolated syndrome (RIS), a term applied to asymptomatic subjects with brain MRI abnormalities highly suggestive of multiple sclerosis. We thus used a multimodal MRI approach on the human brain by modeling measures of microstructural integrity of white matter (WM) tracts with those of functional connectivity (FC) at the level of resting state networks in RIS subjects, demographically matched normal controls (NC), and relapsingremitting (RR) MS patients, also matched with RIS for brain macrostructural damage (i.e., lesions and atrophy). Compared with NC, in both RIS subjects and MS patients altered integrity of WM tracts was present. However, RIS subjects showed, at a less conservative threshold, lower diffusivities than RRMS patients in distinct cerebral associative, commissural, projection, and cerebellar WM tracts, suggesting a relatively better anatomical connectivity. FC was similar in NC and RIS subjects, even in the presence of important risk factors for MS (spinal cord lesions, oligoclonal bands, and dissemination in time on MRI) and increased in RRMS patients in two clinically relevant networks subserving "processing" (sensorimotor) and "control” (working memory) functions. In RIS, the lack of functional reorganization in key brain networks may represent a model of "functional reserve," which may become upregulated, with an adaptive or maladaptive role, only at a later stage in case of occurrence of clinical deficit.

Key words: multiple sclerosis; connectivity; neuroplasticity; radiologically isolated syndrome; resting state networks

\section{Introduction}

The term radiologically isolated syndrome (RIS) is applied to asymptomatic subjects with brain MRI abnormalities highly suggestive of MS (Okuda, 2009). A number of MRI studies have shown that brain tissue damage in RIS shares similarities with that of MS in terms of white matter (WM) lesions (load and mapping), atrophy (De Stefano et al., 2011; Amato et al., 2012), spinal cord lesions (Okuda et al., 2011), cortical lesions (Giorgio et al., 2011), and metabolic changes suggestive of axonal damage (Stromillo et al., 2013).

It is well known that both anatomical and functional connectivity are altered in MS brains (Filippi et al., 2013). Anatomical connectivity is defined by the whole set of WM tracts connecting different gray matter (GM) regions of the brain

Received June 23, 2014; revised Aug. 20, 2014; accepted Sept. 26, 2014.

Author contributions: M.P.A. and N.D.S. designed research; A.G., M.L.S., A.D.L., F.R., B.H., and E.P. performed research; A.G. and I.B. analyzed data; A.G. and N.D.S. wrote the paper.

E.P. serves on scientific advisory boards for Biogen Idec, Merck Serono, and Bayer Schering and receives research support and honoraria for speaking from Biogen Idec, Merck Serono, Bayer Schering Pharma, Teva Pharmaceutical Industries, Novartis, and Sanofi Aventis. N.D.S. has served on scientific advisory boards, received speaker honoraria, served as a consultant, or received research support from BioMS Medical, Biogen Idec, Bayer Schering Pharma, Merck Serono, NeuroRx Research, Novartis, Teva Pharmaceutical Industries, and the Italian Multiple Sclerosis Society. M.P.A. serves on scientific advisory boards for Biogen Idec, Merck Serono, Bayer Schering Pharma, Teva Pharmaceutical Industries, and Sanofi Aventis and receives research support and honoraria for speaking from Biogen Idec, Merck Serono, Bayer Schering Pharma, Teva Pharmaceutical Industries, Novartis, and Sanofi Aventis.

Correspondence should be addressed to Dr. Nicola De Stefano, Department of Medicine, Surgery and Neuroscience, University of Siena, Viale Bracci 2, 53100 Siena, Italy. E-mail: destefano@unisi.it.

DOI:10.1523/JNEUROSCI.2557-14.2015

Copyright $\odot 2015$ the authors $\quad 0270-6474 / 15 / 350550-09 \$ 15.00 / 0$ and is estimated in vivo from diffusion tensor imaging (DTI; Johansen-Berg and Rushworth, 2009). Functional connectivity is studied by means of resting fMRI and reflects the strength of correlated neurophysiological activity in different GM regions of the brain, the so-called resting state networks (RSNs; van den Heuvel and Hulshoff Pol, 2010). In case of disease, resting fMRI provides a powerful approach for the study of neuroplasticity, i.e., the ability of the brain to adapt to injury through functional changes, without the confounding effect of task-related performance (Tomassini et al., 2012). The need of mapping neural connections, which convey information across brain, is prompted by the notion that brain function does not rely only on individual regions but rather depends on interaction patterns across distributed large-scale networks (Catani et al., 2012a).

MS patients show a distributed pattern of abnormalities in brain functional connectivity, which are related to the extent of focal pathology (Rocca et al., 2012; Janssen et al., 2013; Cruz-Gómez et al., 2014) and to altered anatomical connectivity (Rocca et al., 2007; Roosendaal et al., 2010; Hawellek et al., 2011). Importantly, such abnormalities turn out to be clinically meaningful, as demonstrated by their association with physical disability and cognitive impairment (Rocca et al., 2010; Bonavita et al., 2011; Hawellek et al., 2011; Faivre et al., 2012; Loitfelder et al., 2012; Schoonheim et al., 2012; Basile et al., 2013; Janssen et al., 2013; Cruz-Gómez et al., 2014; Gamboa et al., 2014). 
Table 1. Demographic and clinical characteristics of RIS subjects

\begin{tabular}{|c|c|c|c|c|c|c|c|}
\hline Subjects & Sex & Age & Age at first brain MRI & Reason for first brain MRI & DIT on brain MRI & $\mathrm{CSF}^{a}$ & Spinal cord MRI ${ }^{b}$ \\
\hline 1 & $M$ & 46 & 44 & Depression & - & - & - \\
\hline 2 & $\mathrm{~F}$ & 44 & 43 & Anxiety & + & + & n.p. \\
\hline 3 & $\mathrm{~F}$ & 53 & 44 & Facial trauma & - & + & - \\
\hline 4 & $F$ & 53 & 50 & Cervical trauma & + & + & + \\
\hline 5 & M & 38 & 35 & Dermatitis & + & - & - \\
\hline 6 & $\mathrm{~F}$ & 49 & 41 & Cervical trauma & + & + & + \\
\hline 7 & $M$ & 45 & 42 & Neuropathic pain & + & - & - \\
\hline 8 & $\mathrm{~F}$ & 42 & 40 & Dizziness ( < $2 \mathrm{~min}$ ) & - & - & - \\
\hline 9 & $\mathrm{~F}$ & 49 & 40 & MS family history & - & n.p. & + \\
\hline 10 & $\mathrm{~F}$ & 26 & 21 & Pituitary adenoma & + & + & + \\
\hline 11 & M & 33 & 29 & Headache & + & - & - \\
\hline 12 & $\mathrm{~F}$ & 40 & 31 & Migraine with aura & + & + & - \\
\hline 13 & $\mathrm{~F}$ & 26 & 22 & Migraine without aura & + & + & + \\
\hline 14 & $\mathrm{~F}$ & 35 & 34 & Neck pain & + & + & + \\
\hline 15 & M & 53 & 50 & Headache & + & + & - \\
\hline 16 & M & 48 & 45 & Headache & - & n.p. & n.p. \\
\hline 17 & $\mathrm{~F}$ & 20 & 19 & Headache & + & + & + \\
\hline 18 & $\mathrm{~F}$ & 32 & 28 & Suspected pituitary adenoma & + & + & - \\
\hline
\end{tabular}

DIT, dissemination in time; $n$.p., not performed. ${ }^{a}+$, presence of oligoclonal bands and/or abnormal lgG index; - , normal pattern. ${ }^{b}+$, presence of spinal lesion; - , absence of signal abnormalities.

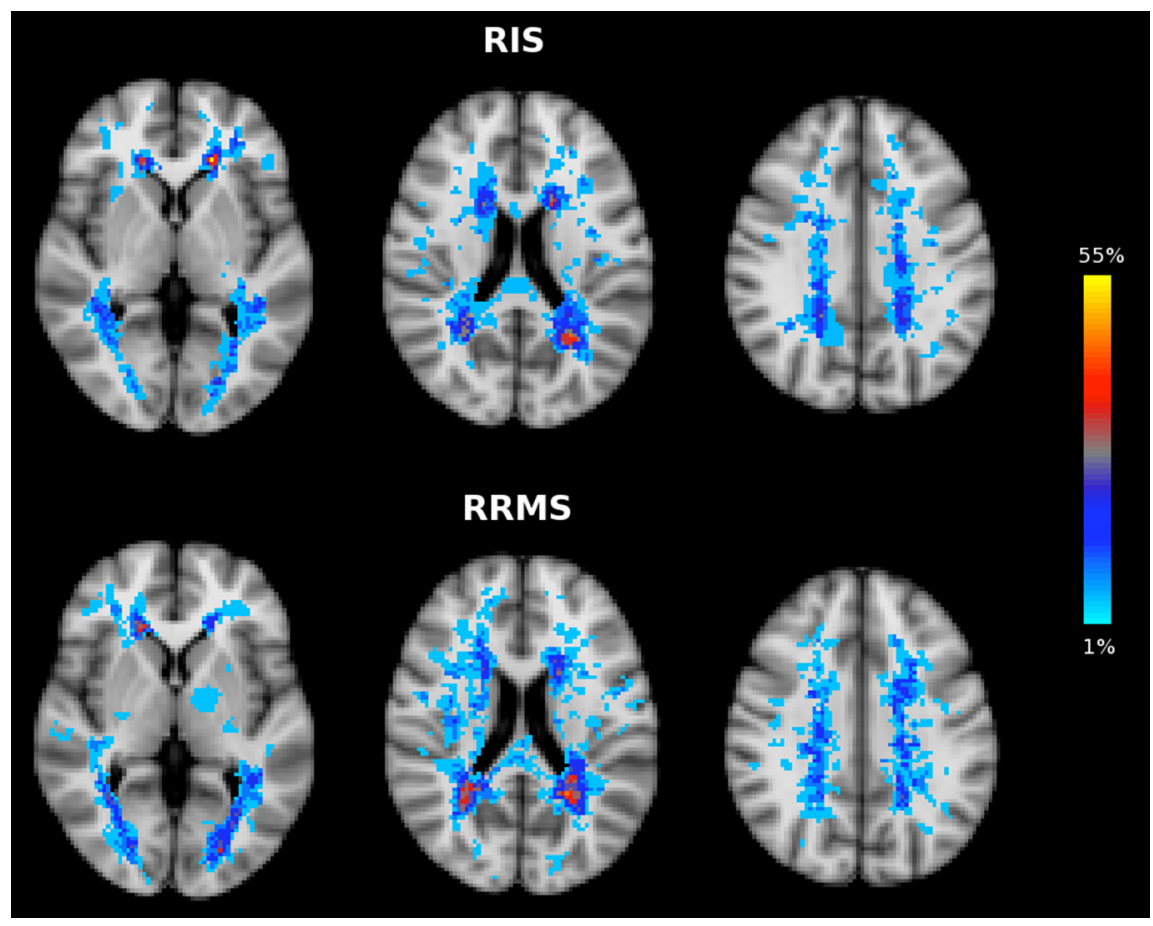

Figure 1. Similar distribution across brain of T2-weighted LPMs in RIS (top) and RRMS (bottom). The color overlay created on top of the MNI standard brain represents the probability of lesion occurrence (lesion frequency) in a particular spatial location. Images are shown in radiological convention.

Given the importance of brain connectivity in clarifying the intimate disease process leading to disability, its appraisal might help shed light on the processes preceding the clinical manifestations of MS. Against this background, we sought to investigate here, through the assessment of brain connectivity at anatomical and functional levels, the relation between tissue damage and neuroplasticity in RIS. Specifically, we aimed to assess across the whole brain of RIS subjects compared with MS patients with similar macrostructural damage and to healthy people (1) changes in the microstructural integrity of WM tracts by tractbased spatial statistics (TBSS) of DTI measures and (2) changes in RSNs by resting fMRI.

\section{Materials and Methods}

\section{Study subjects}

We enrolled asymptomatic subjects fulfilling the diagnostic criteria for RIS (Okuda, 2009; $n=18,12$ females, age $=40.6 \pm 10$ years; Table 1) and included in previously studied cohorts (De Stefano et al., 2011; Giorgio et al., 2011; Stromillo et al., 2013) and also relapsingremitting (RR) MS patients matched with RIS subjects for demographics ( $n=20,12$ females, age $=39.7 \pm 8$ years) and for macrostructural brain damage [T2-weighted lesion volume (LV): $5.4 \pm 6.6 \mathrm{~cm}^{3}$ in RIS, $6.2 \pm 7.1 \mathrm{~cm}^{3}$ in RRMS, $p=0.9$; T1-weighted LV: $2.3 \pm 2.5 \mathrm{~cm}^{3}$ in RIS, $2.6 \pm 2.8 \mathrm{~cm}^{3}$ in RRMS, $p=0.9$; normalized brain volume (NBV): $1505 \pm 13 \mathrm{~cm}^{3}$ in RIS, $1470 \pm 12 \mathrm{~cm}^{3}$ in RRMS; normalized GM volume (NGMV): $764 \pm 43 \mathrm{~cm}^{3}$ in RIS, $746 \pm 40 \mathrm{~cm}^{3}$ in RRMS, $p=0.15$ for both]. RRMS patients had disease duration $=5.1 \pm$ 2.7 years, Expanded Disability Status Scale $=$ $1.7 \pm 1.4$, and 18 of 20 were on diseasemodifying treatments (DMTs) at study entry. As a third study group, we selected a group of demographically matched normal controls $(\mathrm{NC} ; n=20,12$ females, age $=39.4 \pm 9$ years $)$, made up of laboratory and hospital workers with normal neurological examination, no history of neurological disorder, and no focal WM lesions on brain MRI.

The study received approval from the local ethics committee. Informed written consent was obtained from all subjects.

\section{MRI acquisition}

Brain MRI was acquired in all subjects at the NMR Center of the University of Siena using a 1.5 T Philips Gyroscan (Philips Medical Systems). A sagittal survey image was used to identify the anterior and posterior commissure (AC and PC). Sequences were oriented in the axial plane parallel to the AC-PC line. A dual-echo, turbo spin-echo sequence (TR/ echo time TE1/TE2 $=2075 / 30 / 90 \mathrm{~ms}$, voxel size $=1 \times 1 \times 3 \mathrm{~mm}$ ) yielded proton density and T2-weighted images. DTI data consisted of $\mathrm{EPI}\left(\mathrm{TR}=8500 \mathrm{~ms}\right.$; $\mathrm{TE}=100 \mathrm{~ms}$; voxel size $\left.=2.5 \mathrm{~mm}^{3}\right)$, with diffusion weighting distributed in 32 directions and b-value $=1000 \mathrm{~s}^{\star} \mathrm{mm}^{-2}$. Resting fMRI data were 190 volumes of EPI sequence with TR $=1000 \mathrm{~ms}$, $\mathrm{TE}=50 \mathrm{~ms}$, voxel size $=3.75 \times 3.75 \times 6 \mathrm{~mm}$. A high-resolution 
T1-weighted image $(\mathrm{TR}=25 \mathrm{~ms}, \mathrm{TE}=4.6 \mathrm{~ms}$, voxel size $=1 \mathrm{~mm}^{3}$ ) was acquired for brain volume measurement, image registration, and anatomical mapping. Periodical quality assurance sessions were performed and no major hardware upgrade was performed on the scanner during the time of the study.

\section{MRI data analysis}

Brain lesions and atrophy. A single observer visually assessed MRI scans. Labeling of new T2lesions, for the assessment of dissemination in time from a previous MRI, was performed in RIS subjects with a semi-automated segmentation technique based on user-supervised local thresholding (Jim 5.0; Xinapse System; www. xinapse.com/Manual/). T2-weighted lesion probability maps (LPMs) were created in RIS subjects and RRMS patients using a previously described procedure (Rossi et al., 2012; Giorgio et al., 2013).

Global and GM brain atrophy, expressed, respectively, as NBV and NGMV, were quantified in RIS and RRMS on high-resolution T1weighted image using the SIENAx method, part of the FMRIB Software Library ( $\mathrm{w} w \mathrm{w}$. fmrib.ox.ac.uk/f s l/; Smith et al., 2004; Jenkinson et al., 2012). To avoid GM misclassification due to WM lesions, the latter were masked out and refilled with intensities matching the surrounding normal-appearing WM before segmentation analysis (Battaglini et al., 2012).

Analysis of the microstructural integrity of WM tracts. Voxelwise analysis of DTI data from the three study groups was performed across the whole brain using TBSS (Smith et al., 2006) version 1.2, part of FSL. First, DTI data were corrected for MRI eddy currents and head motion using affine registration to a reference volume, i.e., the one without diffusion weighting $(b=0)$. Second, images of fractional anisotropy (FA), axial diffusivity (AD), and radial diffusivity $(\mathrm{RD})$ were created by fitting a tensor model to the raw DTI data using FMRIB Diffusion Toolbox (Behrens et al., 2003) version 3.0, and then brain extracted using Brain Extraction Tool (BET; Smith, 2002). All subjects' FA data were then aligned into a common standard space (FMRIB58_FA) using the nonlinear registration tool FMRIB Nonlinear Image Registration Tool (FNIRT; Andersson et al., 2007a,b), which uses a b-spline representation of the registration warp field (Rueckert et al., 1999). Next, the mean FA image was created and thinned to create a mean FA "skeleton" (thresholded at FA $>0.2$ ), which represents the centers of all WM tracts common to the study groups. Aligned FA data from all study subjects was then projected onto this WM skeleton.

TBSS was also applied to the other DTI-derived data (i.e., AD and RD). To achieve this, FA images were used for nonlinear registration, skeletonization, and projection stages.

The resulting projected (onto the mean WM skeleton) data of $\mathrm{FA}, \mathrm{AD}$, and RD images were finally fed into voxelwise group statistics (see below, Statistics).

Analysis of the brain functional connectivity. It was performed across the whole brain using probabilistic independent component analysis (PICA; Beckmann and Smith, 2004) as implemented in MELODIC version 3.12, also part of FSL. text for abbreviations.

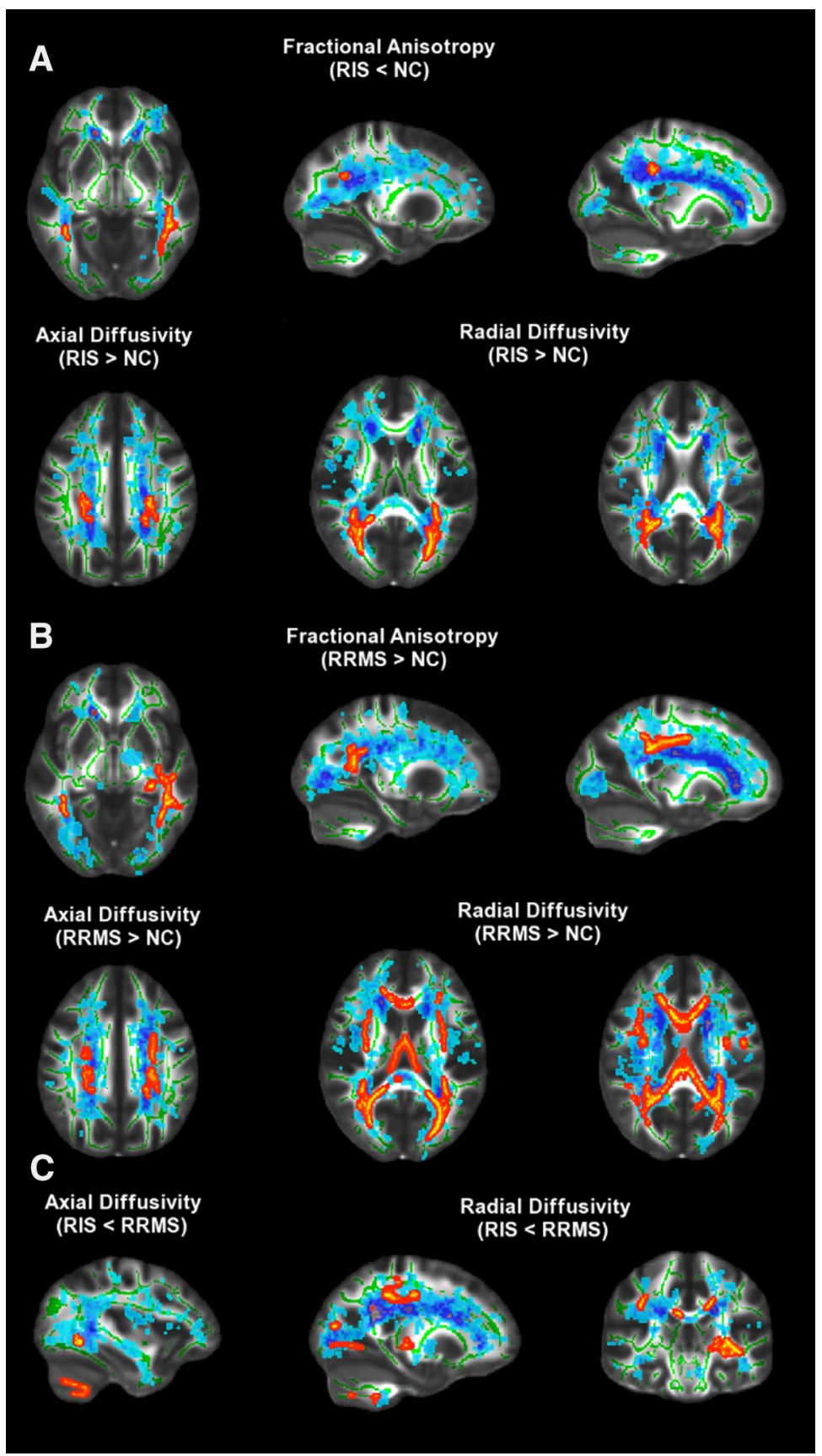

Figure 2. TBSS analysis of DTI measures across the whole brain. Red-yellow shows clusters where RIS subjects $(\boldsymbol{A})$ and RRMS patients $(\boldsymbol{B})$ had DTI abnormalities (lower FA or higher AD and RD; $p<0.01$, corrected) with respect to NC. $\boldsymbol{C}$, Regions of WM tracts where RIS subjects had lower AD and RD than RRMS patients are shown ( $p<0.05$, corrected). Green is the mean WM skeleton. Background image, shown in radiological convention, is the FMRIB58 FA standard space. See Results and Table 2 for details. See tion correction using MCFLIRT (Jenkinson et al., 2002), nonbrain removal using BET (Smith, 2002), spatial smoothing using a Gaussian kernel of $8 \mathrm{~mm}$ full-width at half-maximum, normalization of the whole dataset by a single scaling factor ("grand-mean scaling") to ensure dataset comparability at group level, and high-pass temporal filtering (Gaussianweighted, least-squares straight line fitting, using a cutoff of $100 \mathrm{~s}$ ).

In each subject, registration of resting fMRI data to high-resolution T1-weighted image and standard space (MNI152) was performed using FLIRT (Jenkinson et al., 2002) with boundary-based registration cost function and FNIRT (warp resolution: $10 \mathrm{~mm}$; Andersson et al., $2007 a, b)$. Preprocessed data were then temporally concatenated across 
Table 2. Regions along cerebral WM tracts where RIS subjects showed DTI abnormalities with respect to NC at whole-brain TBSS analysis

\begin{tabular}{|c|c|c|c|c|}
\hline WM regions (local maxima) & Side & MNI $X, Y, Z$ & Cluster size (voxel count) & $t$-stats \\
\hline \multicolumn{5}{|l|}{ Lower FA } \\
\hline Inferior longitudinal fascicle & L & $-41,-31,-15$ & 2563 & 4.95 \\
\hline Inferior fronto-occipital fascicle & R & $39,-45,-4$ & 67 & 4.16 \\
\hline Splenium of the corpus callosum & $\mathrm{R}$ & $17,-35,32$ & 45 & 4.71 \\
\hline Inferior longitudinal fascicle & $\mathrm{R}$ & $38,-48,4$ & 40 & 4.56 \\
\hline Posterior corona radiata adjacent to precuneus cortex & R & $26,-53,25$ & 26 & 3.89 \\
\hline \multicolumn{5}{|l|}{ Higher AD } \\
\hline \multirow[t]{2}{*}{ Posterior corona radiata mapping on the superior longitudinal fascicle } & $\mathrm{L}$ & $-21,-44,31$ & 476 & 4.33 \\
\hline & $\mathrm{R}$ & $26,-36,32$ & 315 & 5.98 \\
\hline \multicolumn{5}{|l|}{ Higher RD } \\
\hline Forceps major & $\mathrm{L}$ & $-29,-54,15$ & 3079 & 4.6 \\
\hline Posterior corona radiata mapping on the inferior fronto-occipital fascicle & $\mathrm{R}$ & $27,-54,23$ & 2527 & 5.53 \\
\hline
\end{tabular}

TFCE, $p<0.01$ corrected. For each DTI metric, regions are ordered according to cluster size.

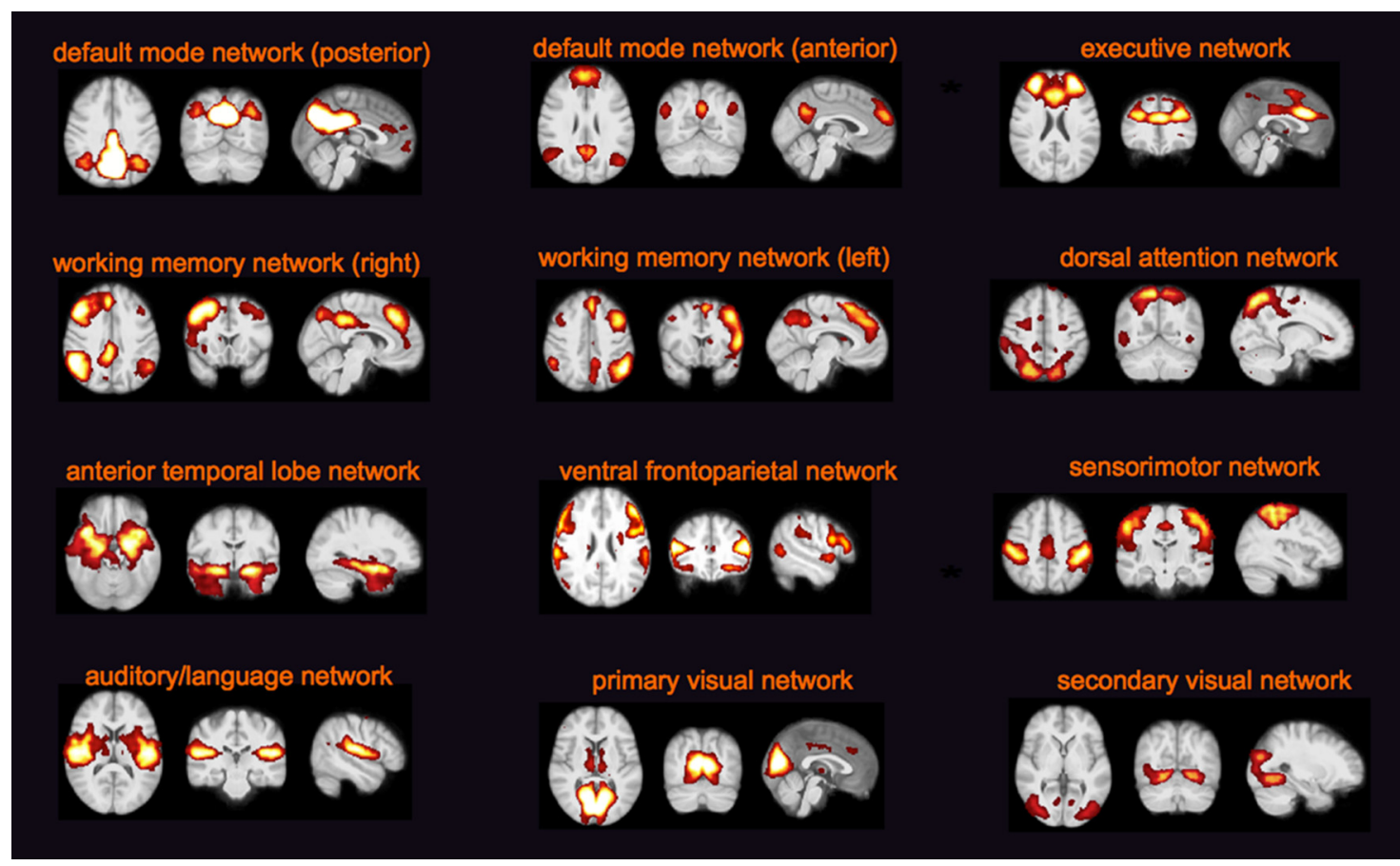

Figure 3. Functionally relevant RSNs (the most informative slices are shown) across study subjects (RIS, RRMS, and NC) identified with PICA. Images (axial, coronal, and sagittal) are z-statistics overlaid on the average high-resolution image transformed into standard space (MNI152). Z values are red to yellow, ranging from 3 to 10 . Images are shown in radiological convention. See text for abbreviations.

subjects to create a single $4 \mathrm{D}$ dataset. Such a dataset was variance normalized and then decomposed into a set of 30 independent components (ICs) using PICA, where the number of dimensions was automatically estimated using the Laplace approximation to the Bayesian evidence of the model order (Beckmann and Smith, 2004). Next, voxelwise analysis of resting fMRI data was performed using the "dual-regression" approach (Beckmann et al., 2009). In stage 1, for each subject the groupaverage set of spatial maps was regressed (as spatial regressors in a multiple regression) into the subject's $4 \mathrm{D}$ space-time dataset. This resulted in a set of subject-specific time courses, one per group-level spatial map. In stage 2, those time courses were regressed (as temporal regressors, again in a multiple regression) into the same $4 \mathrm{D}$ dataset, resulting in a set of subject-specific spatial maps, one per group-level spatial map.

ICs of interest were selected by visual inspection and by comparison with previously defined RSNs (Beckmann et al., 2005; Damoiseaux et al., 2006; De Luca et al., 2006) and reflect "coactivation" or "synchronization" across the network. The remaining ICs represented physiological noise (cardiac, respiratory and CSF pulsations, and head motion), scanner-related artifacts, and misregistrations, and were removed before further analysis.
Statistics. Voxelwise statistical inference for LPM, TBSS, and PICA analyses was performed within the GLM framework with FSL randomize, a nonparametric permutation testing (5000 permutations). A threegroup ANOVA, controlling for age and sex, followed by Bonferronicorrected pairwise comparisons $(p<0.01)$, was used to assess voxelwise differences among the three groups. Thresholding was performed using Threshold-Free Cluster Enhancement (TFCE), fully corrected for multiple comparisons across space. We repeated the functional connectivity comparison analyses also adding GMV as a covariate to the GLM design.

\section{Results}

Lesions

Brain lesions were present in all RIS subjects and RRMS patients. Spinal cord lesions were found in 7 of 18 (i.e., 40\%) RIS subjects and in 14 of 20 (i.e., 70\%) RRMS patients. T2weighted LPMs of RIS and RRMS showed an overall similar distribution across brain (Fig. 1) and no difference in probability of lesion occurrence (lesion frequency) was found at voxelwise analysis. 
Microstructural integrity of white matter tracts

Compared with NC, both RIS subjects and RRMS patients showed altered DTI metrics at TBSS analysis across the whole brain ( $p<0.01$, corrected). In particular (Fig. 2A, Table 2), RIS subjects showed lower FA $(0.49 \pm 0.04$ vs $0.55 \pm 0.02)$ in clusters overlapping lesional areas, with local maxima in the inferior longitudinal fascicle (ILF) bilaterally and in the inferior fronto-occipital fascicle (IFOF), splenium of the corpus callosum (sCC), and posterior corona radiata (CR) adjacent to precuneus cortex on the right. In addition, RIS subjects also showed clusters of altered diffusivities in lesional areas when compared with NC (Fig. 2A, Table 2): higher $\mathrm{AD}(1.27 \pm 0.11$ vs $1.14 \pm 0.03 \times$ $10^{-3} \mathrm{~mm}^{2} / \mathrm{s}$ ) in the posterior CR mapping on the superior longitudinal fascicle (SLF) bilaterally and higher RD $(0.60 \pm$ 0.07 vs $\left.0.51 \pm 0.03 \times 10^{-3} \mathrm{~mm}^{2} / \mathrm{s}\right)$ in the forceps major on the left and in the posterior CR mapping on the IFOF on the right.

RRMS patients showed, similarly to RIS subjects, changes in DTI metrics with respect to NC. These abnormalities mapped on several WM tracts across brain both within lesions and regions of the normal-appearing WM (Fig. $2 B)$ : lower FA $(0.47 \pm 0.03$ vs $0.54 \pm 0.02)$ in the ILF, fornix, and body of the CC on the left, in the IFOF, sCC, and genu of the CC on the right; higher $\mathrm{AD}$ $\left(1.50 \pm 0.14\right.$ vs $\left.1.30 \pm 0.04 \times 10^{-3} \mathrm{~mm}^{2} / \mathrm{s}\right)$ in the CR bilaterally, in the IFOF/ILF on the left, in the posterior limb of the internal capsule on the right; and higher $\operatorname{RD}(0.65 \pm 0.07$ vs $0.54 \pm 0.02 \times$ $\left.10^{-3} \mathrm{~mm}^{2} / \mathrm{s}\right)$ in the posterior $\mathrm{CR}$ on the right, in the anterior thalamic radiation and SLF on the left.

No significant clusters of DTI metrics across brain survived in the comparison analysis between RIS subjects and RRMS patients. However, by using a less conservative threshold (i.e., $p<$ 0.05 , corrected; Fig. 2C) WM of RIS subjects showed, with respect to that (both lesions and normal-appearing WM) of RRMS patients, lower $\operatorname{AD}\left(0.98 \pm 0.06\right.$ vs $\left.1.14 \pm 0.13 \times 10^{-3} \mathrm{~mm}^{2} / \mathrm{s}\right)$ in the IFOF and cerebellum on the left; lower RD $(0.57 \pm 0.03$ vs $0.66 \pm 0.05 \times 10^{-3} \mathrm{~mm}^{2} / \mathrm{s}$ ) in the IFOF, ILF, cerebellum, superior CR mapping on the corticospinal tract on the left; in the body of the CC on the right; and in the SLF bilaterally, while there was no difference in FA. In RIS subjects, no WM regions with higher $\mathrm{AD}$ and $\mathrm{RD}$ than in RRMS patients were found.

\section{Functional connectivity}

No difference was found among RIS subjects, RRMS patients, and $\mathrm{NC}$ in the head movement parameters during resting fMRI acquisition (relative displacement: $0.06 \pm 0.05 \mathrm{~mm}$ in RIS, $0.06 \pm 0.04 \mathrm{~mm}$ in RRMS, $0.06 \pm 0.03 \mathrm{~mm}$ in $\mathrm{NC}, p=0.90$; absolute displacement: $0.26 \pm 0.16 \mathrm{~mm}$ in RIS, $0.32 \pm 0.13 \mathrm{~mm}$ in RRMS, $0.29 \pm 0.20$ in NC, $p=0.52$ ).

PICA across the whole brain of the study population defined 12 functionally relevant RSNs (Fig. 3), including (anterior and posterior) default mode network, executive network, (right and left) working memory network, dorsal attention network, anterior temporal lobe network, ventral frontoparietal network, sensorimotor network, auditory/language network, and (primary and secondary) visual network.
Table 3. The two RSNs (sensorimotor and right working memory) where RIS subjects showed, similarly to NC, lower FC than RMS patients at PICA across the whole brain

\begin{tabular}{ccrll}
\hline & Side & MNI $X, Y, Z(\mathrm{~mm})$ & $\begin{array}{l}\text { Cluster size } \\
\text { (voxel count) }\end{array}$ & $t$-stats \\
\hline $\begin{array}{c}\text { Sensorimotor network } \\
\quad \text { (local maxima) }\end{array}$ & & & & \\
Postcentral gyrus & $\mathrm{R}$ & $68,-10,28$ & 37 & 4.71 \\
& $\mathrm{~L}$ & $-42,-32,50$ & 32 & 5.17 \\
$\begin{array}{c}\text { Working memory network } \\
\quad \text { (local maxima) }\end{array}$ & & & & \\
Middle frontal gyrus & $\mathrm{R}$ & $44,20,46$ & 38 & 5.28 \\
\hline TFC $P<01$ corrected & & & &
\end{tabular}

TFCE, $p<0.01$ corrected.

Two of these RSNs showed group heterogeneity. In particular, RIS subjects had lower functional connectivity than RRMS patients in the sensorimotor network (postcentral gyrus bilaterally) and in the right working memory network (middle frontal gyrus; $p<0.01$, corrected; Fig. 4, Table 3). Similarly to RIS subjects, NC showed lower functional connectivity than RRMS patients in the aforementioned RSNs mapping, respectively, on the postcentral gyrus and right frontal pole ( $p<0.01$, corrected). No voxelwise difference in brain functional connectivity was found between RIS subjects and NC, even at a less conservative threshold $(p<$ 0.05 , corrected). Moreover, we explored functional connectivity in RIS subjects with respect to the other two study groups in the presence of important risk factors for MS (spinal cord lesions $[n=7]$, oligoclonal bands $[n=11]$, dissemination in time on MRI $[n=13$ ] or the combination of them $[n=6]$ ). In all RIS subgroups, functional connectivity values, extracted from clusters of the two aforementioned networks, were lower than in RRMS patients ( $p<0.02$ for all; Fig. 5 ) and similar to NC.

Differences in the above RSNs were retained when also adding GMV as a covariate.

\section{Discussion}

The term RIS refers to a relatively new entity and is applied to asymptomatic subjects who nonetheless present brain MRI ab- 


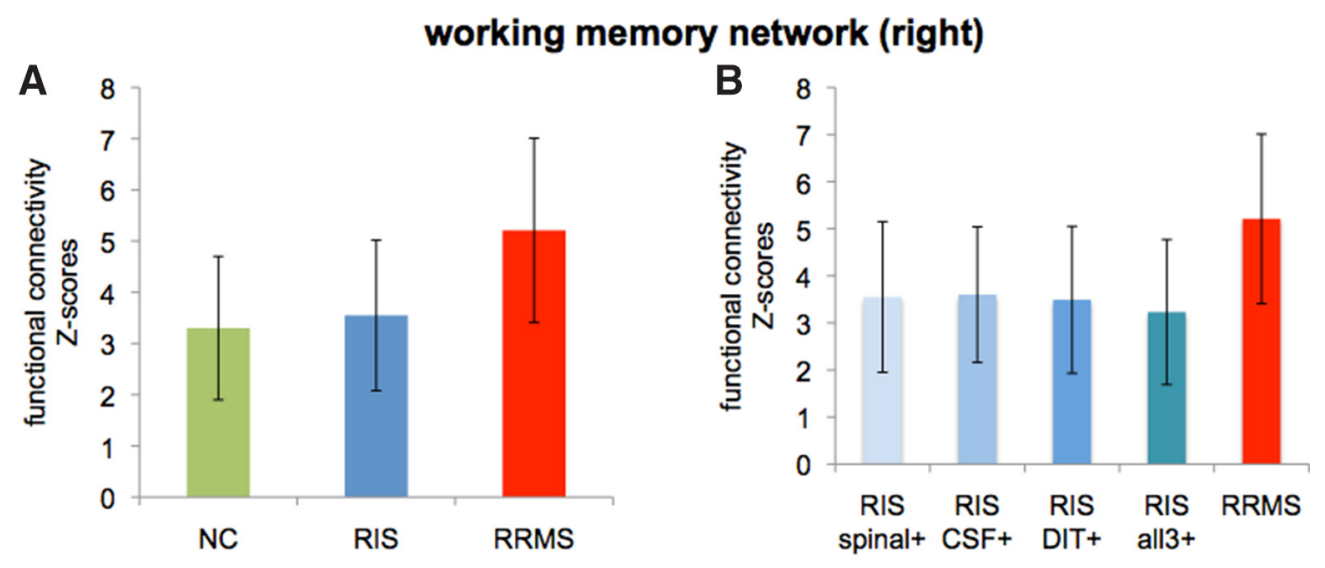

\section{sensorimotor network}
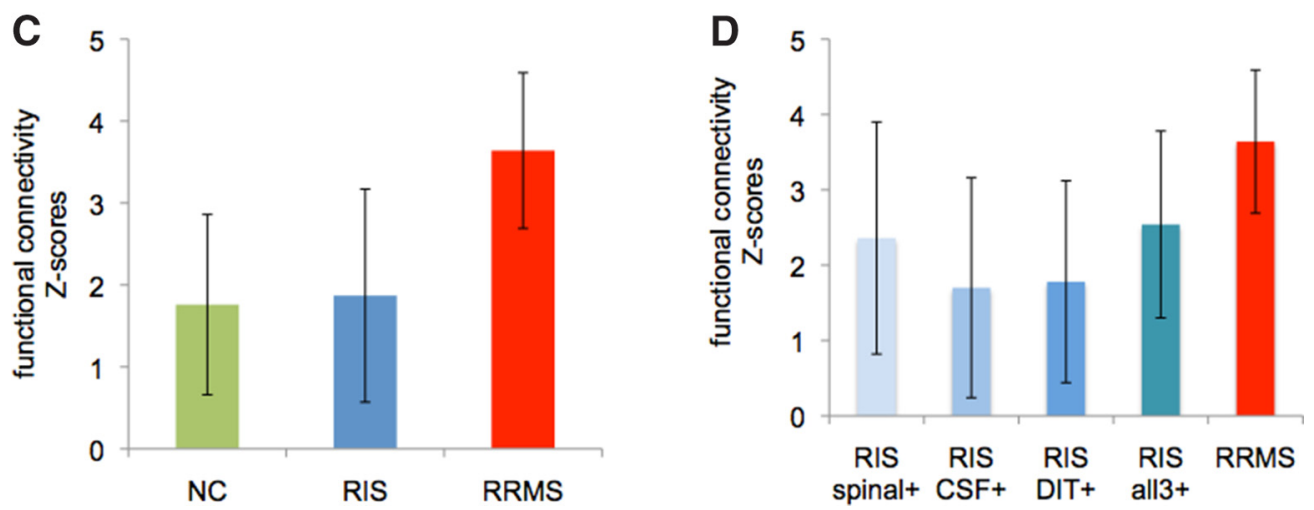

Figure 5. Columns and error bars represent mean and SD of FC values (z scores) averaged across the significant clusters in the right working memory network $(\boldsymbol{A})$ and sensorimotor network ( $\boldsymbol{C}$ ) where RIS subjects showed, similarly to NC, lower FC than RRMS patients. B, D, Show FC values in the subgroups of RIS with risk factors for MS. See Results for details and text for abbreviations.

normalities highly suggestive of MS. The reason this happens has not been fully elucidated yet, but might be related with an exceptional ability to repair and/or to withstand the insult leading to demyelination (Poser, 2004; De Stefano et al., 2011). A number of previous studies (Lebrun et al., 2009; 2010; Okuda et al., 2009; 2011; Siva et al., 2009) have evaluated RIS with conventional MRI, particularly highlighting the similarity with MS in terms of both visible focal and diffuse brain damage (De Stefano et al., 2011; Amato et al., 2012). On the other hand, studies on brain anatomical and functional connectivity in MS have pointed out their relevance in terms of both physical disability and cognitive impairment (Roosendaal et al., 2009; Rocca et al., 2010; 2012; Bonavita et al., 2011; Hawellek et al., 2011; Faivre et al., 2012; Loitfelder et al., 2012; Mesaros et al., 2012; Schoonheim et al., 2012; Basile et al., 2013; Bozzali et al., 2013; Janssen et al., 2013; Li et al., 2013; Cruz-Gómez et al., 2014; Gamboa et al., 2014). To test the hypothesis that brain connectivity would help interpret the absence of clinical deficits in RIS, we assessed it in our RIS subjects in relation to normal controls and to patients with RRMS having similar macrostructural brain damage (i.e., lesions and atrophy).

\section{Microstructural integrity of white matter tracts}

In this study, RIS subjects showed altered integrity of WM tracts with respect to NC only in correspondence of lesions. As expected, in RRMS such abnormalities mapped on both lesions and normal-appearing WM. No voxelwise differences between RIS subjects and RRMS patients were found. However, by using a less conservative statistical thresholding RIS showed lower axial and radial diffusivity and thus a relatively better anatomical connectivity than RRMS along distinct cerebral WM tracts overlapping both lesions and normal-appearing WM and belonging to association (inferior fronto-occipital fascicle and inferior and superior longitudinal fascicles), commissural (corpus callosum), and projection (corticospinal tract) fiber systems and also in the infratentorial region (cerebellum). In general, DTI measures are obtained by fitting a diffusion tensor model to all voxels within the brain. In this context, fractional anisotropy is a sensitive and general measure of microstructural integrity of WM tracts whereas axial and radial diffusivities have been, respectively, proposed as markers of axon and myelin damage in MS animal models and histopathology studies (Song et al., 2005; Sun et al., 2007; Wu et al., 2007; Budde et al., 2008; Schmierer et al., 2008; Wheeler-Kingshott and Cercignani, 2009). The findings reported here are in line with a previous study assessing microstructural integrity of the WM in RIS and MS by using magnetization transfer ratio (De Stefano et al., 2011). Indeed, the presence in RIS of microstructural damage confined to lesions, with a milder severity than in MS, and the lack of involvement of the normalappearing WM, as it occurs in MS, may be among the factors explaining the lack of clinical deficits in these subjects. Overall, it is conceivable the presence of a different degree of myelin and/or axon damage in the two entities is perhaps due to a more beneficial response to it in RIS.

\section{Functional connectivity}

Results of the resting fMRI analysis showed group heterogeneity among NC, RIS subjects, and RRMS patients within two brain 
networks subserving sensorimotor and working memory functions. In particular, functional connectivity in such brain networks was similar between RIS and NC but significantly increased in RRMS. Importantly, the difference in FC between RIS and RRMS was independent from the volume of GM, which was similar in the two groups and also controlled for in the voxelwise analysis.

We found that both RIS subjects and NC had a similar functional connectivity, which was otherwise enhanced in RRMS patients, at the level of the sensorimotor network, a part of the "processing system" of the human brain (Power et al., 2011). This functional change mapped on the postcentral gyrus, an important structure of the parietal lobe and home to the primary somatosensory cortex, which is the main sensory receptive area of the brain. Interestingly, such a region is connected with precentral motor cortex through short frontoparietal U-tracts (central sulcus connections), which play a role in sensorimotor integration and motor learning (Catani et al., 2012b).

Working memory, which is instead part of the "control system" of the human brain (Power et al., 2011), was the other brain network where functional connectivity was decreased in both RIS subjects and $\mathrm{NC}$ with respect to RRMS patients. In particular, change in functional connectivity mapped on the right middle frontal gyrus and frontal pole, both parts of the right prefrontal cortex, which monitors the episodic memory retrieval to respond appropriately or, in other words, to make decisions by weighing the risk-to-benefit ratio (Konishi et al., 2002; Floel et al., 2004; Ranganath, 2004).

Interpretation of the preserved functional connectivity patterns in RIS is inevitably linked to the changes of it, and thus to the neuroplasticity occurring in MS brains (Tomassini et al., 2012). Enhanced functional connectivity in MS has been deemed not only as a compensatory process, i.e., leading to a better clinical status through adaptive plasticity mechanisms (Bonavita et al., 2011; Faivre et al., 2012; Loitfelder et al., 2012; Rocca et al., 2012; Basile et al., 2013; Cruz-Gómez et al., 2014), but also as an undesirable maladaptive plasticity triggered and sustained by disability, as demonstrated by studies of fMRI (Reddy et al., 2002; Hawellek et al., 2011) and magnetoencephalography (Hardmeier et al., 2012). In our asymptomatic RIS subjects, the lack of enhanced functional connectivity may have explanations similar to those of MS patients, although in the opposite direction. First, it can be due to the fact that compensatory adaptive functional reorganization might not yet be needed in absence of a clinical status. In this view, such a process might be only temporarily downregulated, thus representing a model of "functional reserve" called into action just at a later stage, in case of occurrence of a clinical deficit. Second, it may be interpreted as a lack of maladaptive plasticity, which instead would contribute to disability. In general, this process involves multiple functional domains (Nudo, 2006; Bruce et al., 2007) and turns out to be a further challenge to recovery in a chronic condition such as MS. Research in both humans and animal models has begun to identify morphological correlates of maladaptive plasticity at the cellular level, including dendritic and synaptic reorganization, glial remodeling, and altered cell life (Sousa and Almeida, 2012). Finally, we cannot rule out the possibility that preserved functional connectivity in RIS is influenced by the relatively milder microstructural WM damage with respect to the RRMS patients.

Indeed, both regions of preserved functional connectivity in RIS (postcentral gyrus and middle frontal gyrus) are adjacent to the SLF, an important long association pathway connecting frontal and parietal cortices of the same hemisphere and whose diffu- sivity was found to be less altered than in MS patients, thus suggesting a possible link between anatomical and functional connectivity in RIS.

\section{Study strengths and limitations}

There are strengths and limitations in the study. The two wholebrain MRI approaches used for the assessment of structural and functional connectivity feature important methodological aspects: nonlinear registration, which reduces the potential bias coming from registration errors; nonparametric permutation testing with a conservative statistical threshold corrected for multiple comparisons across space, thus protecting against false positive results; and TFCE, which uses the spatial information inherent to the data for computing statistical maps, thus not requiring arbitrary image presmoothing and not depending on an arbitrary initial cluster-forming threshold. Limitations lie in the relatively small sample size of the study groups, in the use by MS patients of DMTs potentially affecting the different sources of the fMRI signal and thus its interpretation (Iannetti and Wise, 2007; Tomassini et al., 2012), in the relatively low resolution of the resting fMRI data, and in the cross-sectional design of the study, which can be generally considered a snapshot of a condition at a given point in time.

\section{Conclusions}

RIS represents a unique model for gauging the relation between brain tissue damage, neurologic condition, and neuroplasticity in the human brain. Our findings suggest that in these asymptomatic subjects there is, compared with MS, a relatively milder microstructural damage of different WM tracts, which to some extent, may contribute to explain the lack of functional reorganization in key brain networks. The latter could represent a model of functional reserve," which may become upregulated, with an adaptive or maladaptive role, only at a later stage in case of occurrence of clinical deficit. Capturing temporal dynamics of brain connectivity changes in RIS subjects who will or will not convert to MS over time with longitudinal studies will certainly help disentangle the aforementioned relation.

\section{References}

Amato MP, Hakiki B, Goretti B, Rossi F, Stromillo ML, Giorgio A, Roscio M, Ghezzi A, Guidi L, Bartolozzi ML, Portaccio E, De Stefano N (2012) Association of MRI metrics and cognitive impairment in radiologically isolated syndromes. Neurology 78:309-314. CrossRef Medline

Andersson JLR, Jenkinson M, Smith S (2007a) Non-linear optimisation. FMRIB technical report TR07JA1 from www.fmrib.ox.ac.uk/analysis/techrep.

Andersson JLR, Jenkinson M, Smith S (2007b) Non-linear registration, aka Spatial normalisation. FMRIB technical report TR07JA2 from www. fmrib.ox.ac.uk/analysis/techrep.

Basile B, Castelli M, Monteleone F, Nocentini U, Caltagirone C, Centonze D, Cercignani M, Bozzali M (2013) Functional connectivity changes within specific networks parallel the clinical evolution of multiple sclerosis. Mult Scler 20:1050-1057. CrossRef Medline

Battaglini M, Jenkinson M, De Stefano N (2012) Evaluating and reducing the impact of white matter lesions on brain volume measurements. Hum Brain Mapp 33:2062-2071. CrossRef Medline

Beckmann CF, Smith SM (2004) Probabilistic independent component analysis for functional magnetic resonance imaging. IEEE Trans Med Imaging 23:137-152. CrossRef Medline

Beckmann CF, DeLuca M, Devlin JT, Smith SM (2005) Investigations into resting-state connectivity using independent component analysis. Philos Trans R Soc Lond B Biol Sci 360:1001-1013. CrossRef Medline

Beckmann CF, Mackay CE, Filippini N, Smith SM (2009) Group comparison of resting-state FMRI data using multi-subject ICA and dual regression. Neuroimage 47:S148. CrossRef

Behrens TE, Woolrich MW, Jenkinson M, Johansen-Berg H, Nunes RG, Clare 
S, Matthews PM, Brady JM, Smith SM (2003) Characterization and propagation of uncertainty in diffusion-weighted MR imaging. Magn Reson Med 50:1077-1088. CrossRef Medline

Bonavita S, Gallo A, Sacco R, Corte MD, Bisecco A, Docimo R, Lavorgna L, Corbo D, Costanzo AD, Tortora F, Cirillo M, Esposito F, Tedeschi G (2011) Distributed changes in default-mode resting-state connectivity in multiple sclerosis. Mult Scler 17:411-422. CrossRef Medline

Bozzali M, Spanò B, Parker GJ, Giulietti G, Castelli M, Basile B, Rossi S, Serra L, Magnani G, Nocentini U, Caltagirone C, Centonze D, Cercignani M (2013) Anatomical brain connectivity can assess cognitive dysfunction in multiple sclerosis. Mult Scler 19:1161-1168. CrossRef Medline

Bruce JM, Bruce AS, Arnett PA (2007) Mild visual acuity disturbances are associated with performance on tests of complex visual attention in MS. J Int Neuropsychol Soc 13:544-548. CrossRef Medline

Budde MD, Kim JH, Liang HF, Russell JH, Cross AH, Song SK (2008) Axonal injury detected by in vivo diffusion tensor imaging correlates with neurological disability in a mouse model of multiple sclerosis. NMR Biomed 21:589-597. CrossRef Medline

Catani M, Dell'acqua F, Bizzi A, Forkel SJ, Williams SC, Simmons A, Murphy DG, Thiebaut de Schotten M (2012a) Beyond cortical localization in clinico-anatomical correlation. Cortex 48:1262-1287. CrossRef Medline

Catani M, Dell'acqua F, Vergani F, Malik F, Hodge H, Roy P, Valabregue R, Thiebaut de Schotten M (2012b) Short frontal lobe connections of the human brain. Cortex 48:273-291. CrossRef Medline

Cruz-Gómez ÁJ, Ventura-Campos N, Belenguer A, Ávila C, Forn C (2014) The link between resting-state functional connectivity and cognition in MS patients. Mult Scler 20:338-348. CrossRef Medline

Damoiseaux JS, Rombouts SA, Barkhof F, Scheltens P, Stam CJ, Smith SM, Beckmann CF (2006) Consistent resting-state networks across healthy subjects. Proc Natl Acad Sci U S A 103:13848-13853. CrossRef Medline

De Luca M, Beckmann CF, De Stefano N, Matthews PM, Smith SM (2006) fMRI resting state networks define distinct modes of long-distance interactions in the human brain. Neuroimage 29:1359-1367. CrossRef Medline

De Stefano N, Stromillo ML, Rossi F, Battaglini M, Giorgio A, Portaccio E, Hakiki B, Malentacchi G, Gasperini C, Santangelo M, Bartolozzi ML, Sormani MP, Federico A, Amato MP (2011) Improving the characterization of radiologically isolated syndrome suggestive of multiple sclerosis. PLoS One 6:e19452. CrossRef Medline

Faivre A, Rico A, Zaaraoui W, Crespy L, Reuter F, Wybrecht D, Soulier E, Malikova I, Confort-Gouny S, Cozzone PJ, Pelletier J, Ranjeva JP, Audoin B (2012) Assessing brain connectivity at rest is clinically relevant in early multiple sclerosis. Mult Scler 18:1251-1258. CrossRef Medline

Filippi M, van den Heuvel MP, Fornito A, He Y, Hulshoff Pol HE, Agosta F, Comi G, Rocca MA (2013) Assessment of system dysfunction in the brain through MRI-based connectomics. Lancet Neurol 12:1189-1199. CrossRef Medline

Floel A, Poeppel D, Buffalo EA, Braun A, Wu CW, Seo HJ, Stefan K, Knecht S, Cohen LG (2004) Prefrontal cortex asymmetry for memory encoding of words and abstract shapes. Cereb Cortex 14:404-409. CrossRef Medline

Gamboa OL, Tagliazucchi E, von Wegner F, Jurcoane A, Wahl M, Laufs H, Ziemann U (2014) Working memory performance of early MS patients correlates inversely with modularity increases in resting state functional connectivity networks. Neuroimage 94:385-395. CrossRef Medline

Giorgio A, Stromillo ML, Rossi F, Battaglini M, Hakiki B, Portaccio E, Federico A, Amato MP, De Stefano N (2011) Cortical lesions in radiologically isolated syndrome. Neurology 77:1896-1899. CrossRef Medline

Giorgio A, Battaglini M, Rocca MA, De Leucio A, Absinta M, van Schijndel R, Rovira A, Tintoré M, Chard D, Ciccarelli O, Enzinger C, Gasperini C, Frederiksen J, Filippi M, Barkhof F, De Stefano N (2013) Location of brain lesions predicts conversion of clinically isolated syndromes to multiple sclerosis. Neurology 80:234-241. CrossRef Medline

Hardmeier M, Schoonheim MM, Geurts JJ, Hillebrand A, Polman CH, Barkhof F, Stam CJ (2012) Cognitive dysfunction in early multiple sclerosis: altered centrality derived from resting-state functional connectivity using magneto-encephalography. PLoS One 7:e42087. CrossRef Medline

Hawellek DJ, Hipp JF, Lewis CM, Corbetta M, Engel AK (2011) Increased functional connectivity indicates the severity of cognitive impairment in multiple sclerosis. Proc Natl Acad Sci U S A 108:19066-19071. CrossRef Medline

Iannetti GD, Wise RG (2007) BOLD functional MRI in disease and phar- macological studies: room for improvement? Magn Reson Imaging 25: 978-988. CrossRef Medline

Janssen AL, Boster A, Patterson BA, Abduljalil A, Prakash RS (2013) Resting-state functional connectivity in multiple sclerosis: an examination of group differences and individual differences. Neuropsychologia 51:2918-2929. CrossRef Medline

Jenkinson M, Bannister P, Brady M, Smith S (2002) Improved optimization for the robust and accurate linear registration and motion correction of brain images. Neuroimage 17:825-841. CrossRef Medline

Jenkinson M, Beckmann CF, Behrens TE, Woolrich MW, Smith SM (2012) Fsl. Neuroimage 62:782-790. CrossRef Medline

Johansen-Berg H, Rushworth MF (2009) Using diffusion imaging to study human connectional anatomy. Annu Rev Neurosci 32:75-94. CrossRef Medline

Konishi S, Hayashi T, Uchida I, Kikyo H, Takahashi E, Miyashita Y (2002) Hemispheric asymmetry in human lateral prefrontal cortex during cognitive set shifting. Proc Natl Acad Sci U S A 99:7803-7808. CrossRef Medline

Lebrun C, Bensa C, Debouverie M, Wiertlevski S, Brassat D, de Seze J, Rumbach L, Pelletier J, Labauge P, Brochet B, Tourbah A, Clavelou P (2009) Association between clinical conversion to multiple sclerosis in radiologically isolated syndrome and magnetic resonance imaging, cerebrospinal fluid, and visual evoked potential: follow-up of 70 patients. Arch Neurol 66:841-846. CrossRef Medline

Lebrun C, Blanc F, Brassat D, Zephir H, de Seze J (2010) Cognitive function in radiologically isolated syndrome. Mult Scler 16:919-925. CrossRef Medline

Li Y, Jewells V, Kim M, Chen Y, Moon A, Armao D, Troiani L, Markovic-Plese S, Lin W, Shen D (2013) Diffusion tensor imaging based network analysis detects alterations of neuroconnectivity in patients with clinically early relapsing-remitting multiple sclerosis. Hum Brain Mapp 34:33763391. CrossRef Medline

Loitfelder M, Filippi M, Rocca M, Valsasina P, Ropele S, Jehna M, Fuchs S, Schmidt R, Neuper C, Fazekas F, Enzinger C (2012) Abnormalities of resting state functional connectivity are related to sustained attention deficits in MS. PLoS One 7:e42862. CrossRef Medline

Mesaros S, Rocca MA, Kacar K, Kostic J, Copetti M, Stosic-Opincal T, Preziosa P, Sala S, Riccitelli G, Horsfield MA, Drulovic J, Comi G, Filippi M (2012) Diffusion tensor MRI tractography and cognitive impairment in multiple sclerosis. Neurology 78:969-975. CrossRef Medline

Nudo RJ (2006) Plasticity. NeuroRx 3:420-427. CrossRef Medline

Okuda DT (2009) Unanticipated demyelinating pathology of the CNS. Nat Rev Neurol 5:591-597. CrossRef Medline

Okuda DT, Mowry EM, Beheshtian A, Waubant E, Baranzini SE, Goodin DS, Hauser SL, Pelletier D (2009) Incidental MRI anomalies suggestive of multiple sclerosis: the radiologically isolated syndrome. Neurology 72: 800-805. CrossRef Medline

Okuda DT, Mowry EM, Cree BA, Crabtree EC, Goodin DS, Waubant E, Pelletier D (2011) Asymptomatic spinal cord lesions predict disease progression in radiologically isolated syndrome. Neurology 76:686-692. CrossRef Medline

Poser CM (2004) Multiple sclerosis trait: the premorbid stage of multiple sclerosis. A hypothesis. Acta Neurol Scand 109:239-243. CrossRef Medline

Power JD, Cohen AL, Nelson SM, Wig GS, Barnes KA, Church JA, Vogel AC, Laumann TO, Miezin FM, Schlaggar BL, Petersen SE (2011) Functional network organization of the human brain. Neuron 72:665-678. CrossRef Medline

Ranganath C (2004) The 3-D prefrontal cortex: hemispheric asymmetries in prefrontal activity and their relation to memory retrieval processes. J Cogn Neurosci 16:903-907. CrossRef Medline

Reddy H, Narayanan S, Woolrich M, Mitsumori T, Lapierre Y, Arnold DL, Matthews PM (2002) Functional brain reorganization for hand movement in patients with multiple sclerosis: defining distinct effects of injury and disability. Brain 125:2646-2657. CrossRef Medline

Rocca MA, Pagani E, Absinta M, Valsasina P, Falini A, Scotti G, Comi G, Filippi M (2007) Altered functional and structural connectivities in patients with MS: a 3-T study. Neurology 69:2136-2145. CrossRef Medline

Rocca MA, Valsasina P, Absinta M, Riccitelli G, Rodegher ME, Misci P, Rossi P, Falini A, Comi G, Filippi M (2010) Default-mode network dysfunction and cognitive impairment in progressive MS. Neurology 74:12521259. CrossRef Medline 
Rocca MA, Valsasina P, Martinelli V, Misci P, Falini A, Comi G, Filippi M (2012) Large-scale neuronal network dysfunction in relapsing-remitting multiple sclerosis. Neurology 79:1449-1457. CrossRef Medline

Roosendaal SD, Geurts JJ, Vrenken H, Hulst HE, Cover KS, Castelijns JA, Pouwels PJ, Barkhof F (2009) Regional DTI differences in multiple sclerosis patients. Neuroimage 44:1397-1403. CrossRef Medline

Roosendaal SD, Schoonheim MM, Hulst HE, Sanz-Arigita EJ, Smith SM, Geurts JJ, Barkhof F (2010) Resting state networks change in clinically isolated syndrome. Brain 133:1612-1621. CrossRef Medline

Rossi F, Giorgio A, Battaglini M, Stromillo ML, Portaccio E, Goretti B, Federico A, Hakiki B, Amato MP, De Stefano N (2012) Relevance of brain lesion location to cognition in relapsing multiple sclerosis. PLoS One 7:e44826. CrossRef Medline

Rueckert D, Sonoda LI, Hayes C, Hill DL, Leach MO, Hawkes DJ (1999) Nonrigid registration using free-form deformations: application to breast MR images. IEEE Trans Med Imaging 18:712-721. CrossRef Medline

Schmierer K, Wheeler-Kingshott CA, Tozer DJ, Boulby PA, Parkes HG, Yousry TA, Scaravilli F, Barker GJ, Tofts PS, Miller DH (2008) Quantitative magnetic resonance of postmortem multiple sclerosis brain before and after fixation. Magn Reson Med 59:268-277. CrossRef Medline

Schoonheim MM, Hulst HE, Landi D, Ciccarelli O, Roosendaal SD, SanzArigita EJ, Vrenken H, Polman CH, Stam CJ, Barkhof F, Geurts JJ (2012) Gender-related differences in functional connectivity in multiple sclerosis. Mult Scler 18:164-173. CrossRef Medline

Siva A, Saip S, Altintas A, Jacob A, Keegan BM, Kantarci OH (2009) Multiple sclerosis risk in radiologically uncovered asymptomatic possible inflammatory-demyelinating disease. Mult Scler 15:918-927. CrossRef Medline

Smith SM (2002) Fast robust automated brain extraction. Hum Brain Mapp 17:143-155. CrossRef Medline

Smith SM, Jenkinson M, Woolrich MW, Beckmann CF, Behrens TE, Johansen-Berg H, Bannister PR, De Luca M, Drobnjak I, Flitney DE, Niazy RK, Saunders J, Vickers J, Zhang Y, De Stefano N, Brady JM, Matthews PM (2004) Advances in functional and structural MR image anal- ysis and implementation as FSL. Neuroimage 23 [Suppl 1]:S208-S219. CrossRef Medline

Smith SM, Jenkinson M, Johansen-Berg H, Rueckert D, Nichols TE, Mackay CE, Watkins KE, Ciccarelli O, Cader MZ, Matthews PM, Behrens TE (2006) Tract-based spatial statistics: voxelwise analysis of multi-subject diffusion data. Neuroimage 31:1487-1505. CrossRef Medline

Song SK, Yoshino J, Le TQ, Lin SJ, Sun SW, Cross AH, Armstrong RC (2005) Demyelination increases radial diffusivity in corpus callosum of mouse brain. Neuroimage 26:132-140. CrossRef Medline

Sousa N, Almeida OF (2012) Disconnection and reconnection: the morphological basis of (mal)adaptation to stress. Trends Neurosci 35:742751. CrossRef Medline

Stromillo ML, Giorgio A, Rossi F, Battaglini M, Hakiki B, Malentacchi G, Santangelo M, Gasperini C, Bartolozzi ML, Portaccio E, Amato MP, De Stefano N (2013) Brain metabolic changes suggestive of axonal damage in radiologically isolated syndrome. Neurology 80:2090-2094. CrossRef Medline

Sun SW, Liang HF, Schmidt RE, Cross AH, Song SK (2007) Selective vulnerability of cerebral white matter in a murine model of multiple sclerosis detected using diffusion tensor imaging. Neurobiol Dis 28:30-38. CrossRef Medline

Tomassini V, Matthews PM, Thompson AJ, Fuglø D, Geurts JJ, JohansenBerg H, Jones DK, Rocca MA, Wise RG, Barkhof F, Palace J (2012) Neuroplasticity and functional recovery in multiple sclerosis. Nat Rev Neurol 8:635-646. CrossRef Medline

van den Heuvel MP, Hulshoff Pol HE (2010) Exploring the brain network: a review on resting-state fMRI functional connectivity. Eur Neuropsychopharmacol 20:519-534. CrossRef Medline

Wheeler-Kingshott CA, Cercignani M (2009) About "axial" and "radial" diffusivities. Magn Reson Med 61:1255-1260. CrossRef Medline

Wu Q, Butzkueven H, Gresle M, KirchhoffF, Friedhuber A, Yang Q, Wang H, Fang K, Lei H, Egan GF, Kilpatrick TJ (2007) MR diffusion changes correlate with ultra-structurally defined axonal degeneration in murine optic nerve. Neuroimage 37:1138-1147. CrossRef Medline 